\title{
Nanomole per Liter per Hour
}

National Cancer Institute

\section{Source}

National Cancer Institute. Nanomole per Liter per Hour. NCI Thesaurus. Code C122218.

A rate unit expressed in nanomole(s) per liter of solution per period of time equal to sixty minutes. 